\section{Wie gefährlich sind Nanopartikel wirklich?}

Das Umweltbundesamt hat in einem aktuellen Bericht eindringlich vor gesundheitlichen Gefahren der Nanotechnik gewarnt. Nanotechnisch optimierte Produkte sind aber längst im Alltag angekommen, zum Beispiel in Lacken, Sonnenschutzmitteln oder Kosmetika. Jetzt fordert die Behörde eine Kennzeichnungspflicht. Wir fragten nach bei der Biologin Dr. Heidi Becker.

? Welche Produkte sollte man nach Einschätzung des Umweltbundesamtes meiden?

Becker: Wir empfehlen, auf Produkte zu verzichten, die Nanomaterialien freisetzen können. Bei fest eingebundenen Nanomaterialien sehen wir keine Risiken, also etwa bei Kohlenstoffnanoröhrchen, die fest in einem Tennisschläger eingebunden sind. Anders ist die Lage bei Textilien, die mit Nanosilberpartikeln versetzt sind, um ihnen biozide Eigenschaften zu verleihen, und z. B. in Krankenhäusern und in Funktionsbekleidung verwendet werden. Aus den Textilien löst sich bereits nach der ersten Wäsche etwa die Hälfte der Partikel heraus. Sie gelangen über das Abwasser in Kläranlagen, wo sie wichtige Bakterien schädigen können. Autoreifen mit Nanopartikeln sollen Abrieb und Rollwiderstand verringern. Aber auch diese Nanopartikel gelangen durch den Abrieb wieder in die Umwelt.

? Wie kann man denn erkennen, dass ein Produkt Nanopartikel enthält?

Becker: Im Moment gar nicht. Deshalb fordern wir eine Kennzeichnungspflicht.
? Es ist nicht das erste Mal, dass über Sicherheitsrisiken dieser Technologie debattiert wird. Warum gerade jetzt diese drastische Warnung?

Becker: Bei all den großen Chancen, die diese Technologie bietet und deren Entwicklung das Umweltbundesamt ebenfalls fördert, ist es wichtig, endlich offen über potenzielle Risiken zu sprechen. In Deutschland und weltweit wurde und wird viel Geld für die Risikoforschung ausgegeben. Da jedoch ständig neue Materialien entwickelt werden, stecken wir diesbezüglich noch in den Kinderschuhen.

? Welche gesundheitlichen Risiken sind bereits bekannt?

Becker: Wichtig ist der inhalative Aufnahmepfad. Die sehr kleinen Partikel gelangen tief in die Lunge und dringen aus den Alveolen in den Körper ein. Über die Blutbahn gelangen sie in weitere Organe und verbleiben dort. Was sie langfristig bewirken, ist noch unklar. Fest steht, dass die Partikel sehr reaktiv sind, sie können Proteine und DNA oxidativ schädigen. Entsprechende Forschungsprojekte werden wir weiter in-

\title{
Nanotechnologie - vom Automobilbau bis zur Kosmetik
}

Von Nanomaterialien spricht man, wenn Strukturen mit Partikeln, Fasern oder Plättchen in mindestens einer Dimension maximal $100 \mathrm{~nm}$ groß sind. Aus dieser Winzigkeit resultieren völlig andere physikalische und chemische Eigenschaften, als man sie von größeren Strukturen kennt. Bereits heute wird die Nanotechnologie vielfach angewendet, z. B. für das Antireflexglas im Armaturenbrett von Autos. Nanopartikel machen Lacke kratzfest, sie ermöglichen miniaturisierte Diagnosesysteme (Lab-ona-Chip) oder sorgen in Kathetern für die antibakterielle Beschichtung. Manche Kosmetika enthalten Nanopartikel. Die Nanotechnologie gilt als eine Schlüsseltechnologie der Zukunft. Man geht davon aus, dass sie in der Chemie, Werkstofftechnik, Biotechnologie, Pharmazie, Medizintechnik und zur Energiegewinnung und -speicherung eingesetzt werden kann.

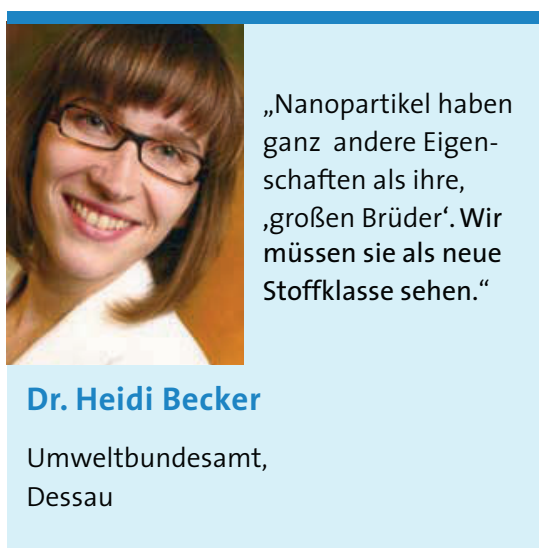

itiieren. Wichtig ist, dass Nanotechnik ein umfassender Begriff für eine sehr heterogene Technologie ist. Es gibt verschiedene chemische Grundmaterialien wie Titandioxid oder Kohlenstoff, es gibt Fasern oder Partikel. Man muss genau unterscheiden, für welche Nanopartikel bestimmte Effekte nachgewiesen sind, für welche nicht. Nur für bestimmte Nanopartikel ist z. B. gezeigt worden, dass sie im Tierversuch zu Entzündungsreaktionen in der Lunge bis hin zu Malignomen führen.

? In ihrem Bericht fordern Sie, dass Hersteller ihre Ergebnisse zur Risikobewertung offenlegen. Heißt das, dass es Risikoprofile gibt, diese aber unter Verschluss gehalten werden?

Becker: Ja, das heißt es. Und hier ist der Gesetzgeber gefragt, um Schaden von der Bevölkerung abzuwenden. Derzeit arbeitet man an Definitionen, die für eine Regulierung in Frage kommen. In der Europäischen Union wird es ab 2012 eine Kennzeichnungspflicht für Kosmetik und neuartige Lebensmittel mit Nanomaterialien geben.

? Sollen Ärzte ihre Patienten mit bestimmten Erkrankungen, etwa der Atemwege oder der Haut, besonders warnen?

Becker: Es ist sehr schwierig, solche Empfehlungen abzugeben, da unser Wissen noch äußerst lückenhaft ist. Eine gute Nachricht ist, dass zum Beispiel intakte Haut eine sehr effektive Barriere für Nanopartikel in Sonnencremes darstellt.

! Vielen Dank für das Gespräch.

Das Interview führte Dr. Thomas Meißner. 